\title{
Characteristics of diabetic foot ulcers in Western Sydney, Australia
}

\author{
Norafizah Haji Zaine ${ }^{1,2}$, Joshua Burns ${ }^{1,2}$, Mauro Vicaretti ${ }^{2,3}$, John P Fletcher ${ }^{2,3}$, Lindy Begg ${ }^{2}$ and Kerry Hitos Li, $^{*}$
}

\begin{abstract}
Background: Australia is ranked ninth of 39 countries in the Western Pacific region most affected by diabetes. Patients with diabetes are at high risk of developing foot ulcerations that can develop into non-healing wounds. Recent studies suggest that the lifetime risk of developing a diabetic foot ulcer is as high as $25 \%$. Few studies have reported the prevalence of, risk factors and socioeconomic status associated with, diabetic foot ulcers in Australia. The aim of this study was to evaluate the characteristics of diabetic foot ulcers in a tertiary referral outpatient hospital setting in Western Sydney, Australia.

Methods: From January-December 2011, a total of 195 outpatients with diabetes were retrospectively extracted for analysis from the Westmead Hospital's Foot Wound Clinic Registry. Data on demographics, socioeconomic status, co-morbidities, foot ulcer characteristics and treatment were recorded on a standardised form.

Results: Demographics and physical characteristics were: $66.2 \%$ male, median age 67 years (IQR: 56-76), median body mass index (BMI) of $28 \mathrm{~kg} / \mathrm{m}^{2}$ (IQR: 25.2-34.1), 75.4\% had peripheral neuropathy and the median postcode score for socioeconomic status was 996 (IQR: 897-1022). Diabetic foot ulcer characteristics were: median cross sectional area of $1.5 \mathrm{~cm}^{2}$ (IQR: 0.5-7.0), median volume of $0.4 \mathrm{~cm}^{3}$ (IQR: $\left.0.11-3.0\right), 45.1 \%$ on the plantar aspect of the foot, $16.6 \%$ UT Wound Grade of OC to 3C (with ischaemia) and $11.8 \%$ with a Grade OD to 3D (with infection and ischaemia) and 25.6\% with osteomyelitis. Five patients required an amputation: 1 major and 4 minor amputations.
\end{abstract}

Conclusions: In accordance with other international studies, foot ulcers are more likely to present on the plantar surface of the foot and largely affect overweight older males with a long standing history diabetes in our outpatient hospital in Western Sydney.

Keywords: Diabetes, Diabetic foot ulcer, Socioeconomic

\section{Background}

Australia is ranked ninth of 39 countries in the Western Pacific region most affected by diabetes [1,2]. People with diabetes have a $25 \%$ lifetime risk of developing foot ulcers, which can develop into chronic non-healing ulcers [3,4]. Chronic ulcers often contain bacterial biofilms that can lead to chronic infections [5]. Foot ulcers may develop due to overlapping factors including neuropathy, peripheral arterial disease, pressure overload, trauma and foot pathologies such as fissures and callosities. Approximately

\footnotetext{
* Correspondence: kerry.hitos@sydney.edu.au

${ }^{2}$ Foot Wound Clinic, Department of Surgery, The University of Sydney, Westmead Hospital, Sydney, NSW, Australia

${ }^{3}$ Westmead Research Centre for the Evaluation of Surgical Outcomes, Department of Surgery, The University of Sydney, Sydney, NSW, Australia Full list of author information is available at the end of the article
}

$40-70 \%$ of lower limb amputations are diabetes-related and $85 \%$ are preceded by foot ulceration [6].

At any point in time, it has been reported in Europe, USA and Africa that $1-11 \%$ of the population with diabetes have an active foot ulcer [7-10]. In the largest database of foot ulcers in Australia [11], Lazzarini et al. examined the characteristics of ambulatory patients with a foot ulcer across 13 Health and Hospital Services and reported that of 2,034 people presenting with a foot ulcer, $85 \%$ had a history of diabetes. The ANDIAB (Australian National Diabetes Information Audit \& Benchmarking) Report of adults with diabetes found that $1.7 \%$ had a current foot ulcer in 2009 which increased to $2.1 \%$ in 2011 [12,13]. The large EURODIALE (European Study Group 
on Diabetes and the Lower Extremity) Project across 14 European centres in 2003 to 2004 [14], identified peripheral arterial disease (PAD) and peripheral neuropathy as the major risk factors in the development of diabetic foot ulcers [15].

The Australian Diabetes Society recommends that people with a foot ulcer are cared for by a multidisciplinary team [16]. The Westmead Hospital's Foot Wound Clinic is an interdisciplinary clinic which is attended concurrently by podiatrists, vascular consultants and registrars, wound care consultants, vascular clinical nurse consultants and a clinic nurse. Infectious Disease Consultants are also available upon request [17]. The Australian National Evidence-Based Guidelines on foot complications in diabetes highlights the importance of understanding the characteristics of an ulcer to help monitor the response of an ulcer to treatment [18]. There have been no studies reporting primarily on characteristics of, risk factors and socioeconomic status associated with, diabetic foot ulcers in Western Sydney, Australia.

The primary aim of this study was to evaluate the characteristics of diabetic foot ulcers in patients presenting to a tertiary referral outpatient hospital setting in Western Sydney, Australia. The secondary aim was to evaluate the use of vascular investigations and off-loading modalities in this high risk group of patients.

\section{Methods}

Ethical approval was granted from the Research Ethics Committees at the Western Sydney Local Health District and The University of Sydney. The study population was defined as the total number of patients with Type 1 Diabetes Mellitus (Type 1 DM) and Type 2 Diabetes Mellitus (Type 2 DM) with foot ulcers at initial visit attending our outpatient Foot Wound Clinic at Westmead Hospital between January to December 2011. Diabetes Mellitus was defined according to the criteria set by the World Health Organisation (WHO). The current WHO diagnostic criteria for Diabetes Mellitus includes a fasting plasma glucose $\geq 7.0 \mathrm{mmol} / \mathrm{l}(126 \mathrm{mg} / \mathrm{dl})$ or 2-hour plasma glucose $\geq 11.1 \mathrm{mmol} / \mathrm{l}(200 \mathrm{mg} / \mathrm{dl})$ [19]. A foot ulcer was defined as a full-thickness wound located distal to the ankle (level of malleoli) [20].

All data were captured in Westmead Hospital's Wound Clinic Registry. Data were extracted on a standardised data collection form. For inconsistencies, clarification was sought from the treating clinician or the patient medical record. Patients without diabetes and without foot ulcers were excluded from the study. Background data included patient characteristics such as demographics details, socioeconomic factors, marital status, country of birth and English language status (defined as patients who were English and non English speaking). Other patient characteristics included co-morbidities such as neuropathy, hyperlipidaemia, retinopathy and history of amputation and/or ulceration.

Peripheral neuropathy was diagnosed by a Podiatrist using a neurothesiometer, $128 \mathrm{~Hz}$ tuning fork or $10 \mathrm{~g}$ monofilament. Investigations of diabetic foot ulcer related factors (such as PAD and ulcer infection), referrals to other health professionals, treatments (such as pressure offloading) and hospitalisation and/or requiring vascular or surgical interventions were also recorded. PAD was assessed and diagnosed by measuring toe pressures using a photoplethysmography (Hadeco Smartdop 30 EX Vascular Ultrasound Doppler). A toe pressure of $<55 \mathrm{mmHg}$ indicates PAD in a foot $[21,22]$.

The socioeconomic status was based on the Australian Bureau of Statistics (ABS) residential postcode method for the general Australian population (mean index = 1000) [23]. The Index of Relative Socioeconomic Disadvantage (IRSD) is used by the ABS as a general socio-economic index to summarise a range of information about the economic and social conditions of people and households within an area. A low score indicates relatively greater disadvantage whereas a high score indicates relatively advantage in general [24]. A score of less than 1000 indicates that the area is more disadvantaged than the average area at the Statistical Area Level 1 (SA1). SA1 is the smallest geographical unit at which the SEIFA (Socio-Economic Indexes For Areas) indexes are calculated [25].

Information on osteomyelitis, Charcot foot and diabetic foot ulcer PEDIS grades of infection (skin/subcutaneous), size, location, infection, history of previous ulceration and lower extremity amputation were recorded [26]. According to the PEDIS classification, grades of infection were defined as, Grade 1: No symptoms or signs, Grade 2: Inflammation of skin/subcutaneous tissues only, Grade 3: Extensive erythema deeper $(>2 \mathrm{~cm})$ than skin/subcutaneous tissues and Grade 4: Systemic inflammatory response syndrome) [26]. The probe to bone technique was used to diagnose osteomyelitis in diabetic foot ulcers [27]. The University of Texas (UT) Diabetic Wound Classification System was used to classify diabetic foot ulcers into a single validated grading system [28].

Foot ulcer duration was categorised into $<1$ week, 1 week to 3 months and $>3$ months [14]. In our study, re-ulceration was used to define a previous foot ulcer that has re-ulcerated on the same location. A patient with a history of a foot ulcer was defined as a patient who had an ulcer on any location of either foot. If more than one ulcer was present, the primary ulcer was defined by the ulcer with the largest cross sectional area $\left(\mathrm{cm}^{2}\right)$ [15,20]. UT Wound Classification of OA and OC are considered completely epithelialized [18]. A traumatic event was defined as an acute injury such as a footwear rub, blister or plantar pressure overload. 


\section{Statistical analysis}

Descriptive statistics to characterise the study sample were generated using SPSS 21.0 (IBM SPSS Statistics for Windows, Armonk, NY, USA). Normality of data distribution was assessed using the Kolmogorov-Smirnov test with Lilliefors significance correction. As such, continuous data are presented as median and interquartile range (IQR, 25 $5^{\text {th }}$ and $75^{\text {th }}$ quartiles). Continuous data were compared using the Mann Whitney $U$ test and proportions using the chi squared $\left(x^{2}\right)$ test. All inferential tests were two tailed and statistical significant differences were considered at the $\mathrm{P}<0.05$ level.

\section{Results}

\section{Patient demographics, risk factors and co-morbidities}

Overall, 318 patients were initially extracted from Westmead Hospital's Wound Clinic Registry and data from 195 (61.3\%) patients with a diabetic foot ulcer at their initial visit were analysed. The remaining 123 (38.4\%) patients were excluded due to no history of diabetes.

Demographics and patient characteristics are shown in Table 1 . The male to female ratio was $2: 1$, with a male median age of 65 years (IQR: 56-76) and a female median age of 69.5 years (IQR: $56-76)(\mathrm{P}=0.154)$. Of 165 (85\%) patients with diabetes duration data, 9.1\% were $<5$ years, $11.5 \%$ were $5-10$ years and $79.4 \%$ were $>10$ years duration. More than $70 \%$ of patients with BMI data $(\mathrm{n}=121)$ were overweight or obese $\left(\mathrm{BMI} \geq 25 \mathrm{~kg} / \mathrm{m}^{2}\right)$. A total of $96(49 \%)$ patients were born overseas and were generally (88.8\%) English speaking individuals. The two most prevalent co-morbidities were neuropathy (75.4\%) and hypertension (67.2\%). Over $50 \%$ of patients with diabetic foot ulcers were smokers or ex smokers. A total of $41.5 \%$ of patients had a history of foot ulcer on another location on the foot. The complete list of medical history and lifestyle risk factors are shown in Table 2.

The median socioeconomic index score was 996 (IQR: 897-1022) which ranked in decile 6 and in the $51^{\text {st }}$ percentile for Australia (Table 1). Of the 82 (42.1\%) patients with a diabetic foot ulcer from relatively advantaged areas (IRSD score >1000), 31 (38\%) had a history of ulceration and $23(28 \%)$ had a history of amputation. Of the 113 (57.9\%) patients from relatively disadvantaged areas (IRSD score of <1000), 49 (43\%) had a history of ulceration and $41(36 \%)$ had a history of amputation. There was no significant difference between history of ulceration $(\mathrm{P}=0.367)$ and amputation $(\mathrm{P}=0.227)$ in IRSD scores.

\section{Foot ulcer characteristics}

In total, $96.4 \%$ of diabetic foot ulcers were recorded as new ulcers during the initial visit and seven (3.6\%) were recorded as reulcerations. Of the 195 patients with diabetic foot ulcers, more than a third (35.4\%) had multiple ulcers. Primary ulcer characteristics and UT Wound
Table 1 Demographics of the sample

\begin{tabular}{|c|c|}
\hline Variable & Total participants \\
\hline Age (median years, IQR ${ }^{\ddagger}$ ), $\mathrm{n}=195$ & $67(56-76)$ \\
\hline Gender, Male, no. (\%), n = 195 & $129(66.2 \%)$ \\
\hline Height (median metres, $\mathrm{IQR}^{\ddagger}$ ), $\mathrm{n}=129$ & $1.7(1.6-1.8)$ \\
\hline Weight (median $\mathrm{kg}, \mathrm{IQR} \mathrm{R}^{\ddagger}$ ), $\mathrm{n}=132$ & $84.5(70.3-101.0)$ \\
\hline BMI (median $\mathrm{kg} / \mathrm{m}^{2}, \mathrm{IQR}^{\ddagger}$ ), $\mathrm{n}=122$ & $28(25.2-34.1)$ \\
\hline \multicolumn{2}{|l|}{ BMI category*, no. (\%), $n=121$} \\
\hline Underweight & $4(3.3 \%)$ \\
\hline Normal & $23(19 \%)$ \\
\hline Overweight & $43(35.5 \%)$ \\
\hline Obese & $36(29.8 \%)$ \\
\hline Morbidly Obese & $15(12.4 \%)$ \\
\hline Socioeconomic ${ }^{\#}$ (median score, $\mathrm{IQR}^{\ddagger}$ ), $\mathrm{n}=193$ & $996(897-1022)$ \\
\hline \multicolumn{2}{|l|}{ Nationality, no. (\%), n= 195} \\
\hline Australian born & $99(50.8 \%)$ \\
\hline Born overseas & $96(49.2 \%)$ \\
\hline \multicolumn{2}{|l|}{ Marital Status, no. (\%), n= 195} \\
\hline Married or De Facto & $114(58.5 \%)$ \\
\hline Widowed & $25(12.8 \%)$ \\
\hline Single & $55(28.2 \%)$ \\
\hline Other & $1(0.5 \%)$ \\
\hline Duration of DM (median years, $I Q R^{\ddagger}$ ), $\mathrm{n}=165$ & $17(11-25)$ \\
\hline
\end{tabular}

*Overweight was defined as BMI 25.0-29.9 kg/m² ; Obese was defined as BMI $30.0-39.9 \mathrm{~kg} / \mathrm{m}^{2}$; Morbidly Obese was defined as BMI $>40.0 \mathrm{~kg} / \mathrm{m}^{2}$.

\#Australia Bureau Statistics postcode score.

${ }^{\ddagger}$ IQR: $25^{\text {th }}$ to $75^{\text {th }}$ percentile.

Table 2 Medical history and lifestyle risk factors of the sample $(n=195)$

\begin{tabular}{ll}
\hline Factor & Number (\%) \\
\hline Neuropathy & $147(75.4 \%)$ \\
Hypertension & $131(67.2 \%)$ \\
Hyperlipidaemia & $107(54.9 \%)$ \\
History of ulcer (Healed) & $81(41.5 \%)$ \\
Retinopathy & $77(39.5 \%)$ \\
History of amputation & $64(32.8 \%)$ \\
Angina/Infarct & $47(24.1 \%)$ \\
Nephropathy & $43(22.1 \%)$ \\
Renal Failure & $26(13.3 \%)$ \\
Claudication & $22(11.3 \%)$ \\
Cerebrovascular Accident & $21(10.8 \%)$ \\
Transient Ischaemic Attack & $15(7.7 \%)$ \\
Charcot Arthropathy & $11(5.6 \%)$ \\
Smoking & \\
Smoker & $28(14.5 \%)$ \\
Ex smoker & $83(42.6 \%)$ \\
\hline
\end{tabular}


Classifications are shown in Tables 3 and 4 respectively. The median cross sectional area of the primary ulcer was $1.5 \mathrm{~cm}^{2}$ (IQR: $0.5-7.0 \mathrm{~cm}^{2}$ ) and volume was $0.4 \mathrm{~cm}^{3}$ (IQR: 0.1-3.0 $\mathrm{cm}^{3}$ ). Ulcer cross sectional area was $<1 \mathrm{~cm}^{2}$ in $42 \%$ of cases, between 1 and $5 \mathrm{~cm}^{2}$ in $30 \%$ of cases, and $>5 \mathrm{~cm}^{2}$ in $28 \%$ of cases. Over one third $(36.4 \%)$ of foot ulcers were located on the forefoot and over $45.1 \%$ were located on the plantar aspect of the foot. The duration of the ulcers at initial visit was $<1$ week for one patient $(0.6 \%), 1$ week to 3 months in $(83.4 \%)$ of patients and $>3$ months in $16.0 \%$ of patients. The greatest ulcer duration was 208 weeks at initial visit. Predominant UT wound types consisted of category $1 \mathrm{~A}$ (33.7\%), 1B (14.0\%) and 3B (11.9\%) (Table 4).

The infection status of each ulcer was graded using the PEDIS system [26]. Almost (49.7\%) of all ulcers were infected and the most prevalent was Grade $2(21.5 \%)$ and Grade 3 (26.7\%) (Table 5). A total of 50 (25.6\%) patients with a diabetic foot ulcer presented with osteomyelitis, and of these $34(17.4 \%)$ were positively diagnosed using the probe to bone technique with 14 (7.2\%) confirmed by

Table 3 Primary ulcer characteristics of the sample

\begin{tabular}{|c|c|}
\hline Characteristic & Total participants \\
\hline \multicolumn{2}{|l|}{ Anatomical Region, $n=195$} \\
\hline Hallux, no. (\%) & $41(21 \%)$ \\
\hline Digits, no. (\%) & 29 (14.9\%) \\
\hline Forefoot, no. (\%) & $71(36.4 \%)$ \\
\hline Midfoot, no. (\%) & $16(8.2 \%)$ \\
\hline Heel, no. (\%) & $38(19.5 \%)$ \\
\hline \multicolumn{2}{|l|}{ Location, $n=195$} \\
\hline Plantar, no. (\%) & $88(45.1 \%)$ \\
\hline Dorsal, no. (\%) & $29(14.9 \%)$ \\
\hline Lateral, no. (\%) & $27(13.8 \%)$ \\
\hline Medial, no. (\%) & $21(10.8 \%)$ \\
\hline Apex, no. (\%) & $30(15.4 \%)$ \\
\hline \multicolumn{2}{|l|}{ Side, $n=195$} \\
\hline Right, no. (\%) & $95(48.7 \%)$ \\
\hline Left, no. (\%) & $100(51.3 \%)$ \\
\hline Duration (weeks), $n=169$ median (IQR*) & $6(3-16)$ \\
\hline < 1 week, no. (\%) & $1(0.6 \%)$ \\
\hline 1 week - 3 months (12 weeks), no. (\%) & $141(83.4 \%)$ \\
\hline > 3 months (12 weeks), no. (\%) & $27(16.0 \%)$ \\
\hline \multicolumn{2}{|l|}{ Size } \\
\hline Length (median $\mathrm{cm}, \mathrm{IQR} \mathrm{R}^{*}$ ), $\mathrm{n}=184$ & $1.5(0.8-3)$ \\
\hline Width (median cm, IQR*), $\mathrm{n}=184$ & $1(0.5-2.0)$ \\
\hline Depth (median cm, IQR*), $\mathrm{n}=183$ & $0.2(0.1-0.8)$ \\
\hline Cross sectional area (median $\mathrm{cm}^{2}, \mathrm{IQR}^{*}$ ), $\mathrm{n}=183$ & $1.5(0.5-7.0)$ \\
\hline Volume (median $\mathrm{cm}^{3}, \mathrm{IQR}^{*}$ ), $\mathrm{n}=182$ & $0.4(0.11-3.0)$ \\
\hline
\end{tabular}

*IQR: $25^{\text {th }}$ to $75^{\text {th }}$ percentile. imaging. The total of 34 foot ulcers diagnosed using probe to bone were also classified using the University of Texas Wound Classification System (Table 4). Approximately $67.7 \%$ of ulcers were attributed to traumatic events. The causes of foot ulceration were post surgery $(8.2 \%)$, traumatic event (67.7\%), other (23.6\%) and unknown (0.5\%).

\section{Pressure off-loading}

At the initial visit, the two most commonly prescribed offloading modalities were the Darco Medical Surgical postop shoe (29.9\%) and Sports/Orthopaedic shoes (15.4\%). Three patients $(1.5 \%)$ were provided with irremovable total contact cast (TCC) and two patients (1.0\%) with removable TCC. All TCC (irremovable and removable) were fibreglass casts constructed with $3 \mathrm{M}$ Softcast and Primacast according to our standardised protocol [29]. In total $15 \%$ of patients had other types of off-loading modalities which included air mattress for pressure offloading, $12 \mathrm{~mm}$ Poron combination innersole, Forefoot Wedge Shoe and Eggshell Foam Boot.

\section{Vascular investigations}

Thirty-one patients were referred for further vascular investigations. Of these, 16 (52\%) were referred for endovascular, 7 (23\%) for duplex arterial ultrasound, 6 (19\%) for diagnostic angiogram and 2 (6\%) for both endovascular and diagnostic angiogram. The predominant UT Wound grades for these 31 patients were $1 \mathrm{C}(22.6 \%)$ and 1D (19.3\%).

\section{Clinical outcome}

A total of $5(2.6 \%)$ patients required an amputation after their initial visit (Table 6). Of these, 3 (60\%) patients were from a relatively greater disadvantaged area (IRSD score of $<1000$ ) and only one had a history of amputation. Four of the $5(90 \%)$ patients had neuropathy and 3 (60\%) were non-smokers. The type and time to amputations are shown in Table 5. There were no deaths during the period of study.

\section{Discussion}

This is the first study to report characteristics of diabetic foot ulcers from Westmead Hospital's Foot Wound Clinic Registry. This may also be the largest study in Australia to date investigating the classification, characteristics, location of diabetic foot ulcers and the patients' socioeconomic status. Patients with diabetic foot ulcers were predominantly male with long-standing diabetes. A similar retrospective study conducted with 181 patients in Victoria reported $61.3 \%$ male predominance [30]. About a third of patients with foot ulcers had a history of ulceration and amputation which are known risk factors for subsequent ulceration [31]. Wu and Armstrong showed 
Table 4 Primary ulcer grade/depth according to The University of Texas Classification System for diabetic foot wounds [17]

\begin{tabular}{|c|c|c|c|c|c|}
\hline & \multicolumn{5}{|l|}{ Grade/Depth N = 193} \\
\hline & & 0 & 1 & 2 & 3 \\
\hline & & $\begin{array}{l}\text { Pre- or post- ulcerative } \\
\text { lesion completely } \\
\text { epithelialised }\end{array}$ & $\begin{array}{l}\text { Superficial wound } \\
\text { not involving tendon, } \\
\text { capsule or bone }\end{array}$ & $\begin{array}{l}\text { Wound penetrating } \\
\text { to tendon or capsule }\end{array}$ & $\begin{array}{l}\text { Wound penetrating } \\
\text { to bone or joint }\end{array}$ \\
\hline \multirow{4}{*}{$\begin{array}{l}\text { Stage/Comorbidities } \\
N=193\end{array}$} & A & $n=0$ & $n=65(33.7 \%)$ & $\mathrm{n}=5(2.6 \%)$ & $\mathrm{n}=3(1.6 \%)$ \\
\hline & B With infection & $\mathrm{n}=0$ & $n=27(14.0 \%)$ & $n=15(7.8 \%)$ & $n=23(11.9 \%)$ \\
\hline & C With ischaemia & $\mathrm{n}=1(0.5 \%)$ & $n=18(9.3 \%)$ & $\mathrm{n}=2(1.0 \%)$ & $\mathrm{n}=2(1.0 \%)$ \\
\hline & $\begin{array}{l}\text { D With infection and } \\
\text { ischaemia }\end{array}$ & $\mathrm{n}=0$ & $n=14(7.3 \%)$ & $\mathrm{n}=7(3.6 \%)$ & $n=11(5.7 \%)$ \\
\hline
\end{tabular}

that between $20-58 \%$ of patients with diabetic foot ulcers develop another ulcer within a year after healing [32].

In our study, three-quarters of patients had a comorbidity of neuropathy which is one of the most common risk factors for developing a diabetic foot ulcer. Over half of patients in this study were smokers or ex-smokers which is a strong risk factor for peripheral arterial disease [33]. The EURODIALE studies highlighted peripheral arterial disease (49\%) and neuropathy $(86 \%)$ as two major risk factors of diabetic foot ulcerations [14].

The median age of our patients was 67 years, which is comparable to the retrospective study conducted in Victoria reporting a mean age of 64.2 years [30]. Increasing age may be a contributory intrinsic factor to chronic wounds as the skin can easily damage [34]. Older cells do not proliferate as fast and may not have an adequate response to stress in terms of gene up regulation of stressrelated proteins [34]. Over half of all patients were overweight and obese/morbidly obese which increases the risk of cardiac-related disease and makes offloading more difficult. Obese patients may also experience compromised wound healing due to poor blood supply to adipose tissue [35].

Westmead Hospital has a large catchment area and is culturally diverse with a variable socioeconomic mix [23]. According to the Postal Area (POA) spreadsheet for IRSD,

Table 5 PEDIS classification grades of infection $(n=195)$

\begin{tabular}{ll}
\hline Grades of infection & Number (\%) \\
\hline Grade 1 No symptoms or signs & $12(6.2 \%)$ \\
Grade 2 Inflammation of skin/subcutaneous & $42(21.5 \%)$ \\
$\quad$ tissues only & $52(26.7 \%)$ \\
Grade 3 Extensive erythema deeper $(>2 \mathrm{~cm})$ & \\
$\quad$ than skin/subcutaneous tissues & $3(1.5 \%)$ \\
Grade 4 Systemic inflammatory response & \\
$\quad$ syndrome & $86(44.1 \%)$ \\
\hline
\end{tabular}

an area code with a score of 996 would be ranked in decile 6 and in the $51^{\text {st }}$ percentile [36]. This indicates that the area is more relatively advantaged than $50 \%$ of the areas and more relatively disadvantaged than $49 \%$ of areas. Our median socioeconomic index score of 996 reflects a marginally lower than median index score of 1000 . There are no studies evaluating the socioeconomic status of patients with diabetic foot ulcers in Australia and whether it is associated with an increased incidence in ulceration. This is the first study exploring the socioeconomic index scores of ambulatory Australian patients diabetic foot ulcer.

Forefoot and digital (including hallux) ulcers were present in $72.3 \%$ of patients. This finding is comparable to $77 \%$ reported in the EURODIALE study and to a Turkish study investigating predominantly acute and chronic diabetic foot ulcers (78\%) [15,37]. Diabetic foot ulcers are commonly located on the plantar aspect of the foot due to abnormal loading and the presence of neuropathy [38]. As such offloading is an important therapeutic option. In the EURODIALE study, $78 \%$ of patients received some form of off-loading. Thirty five percent of patients were prescribed a TCC or another casting modality and the majority of plantar ulcers, like our study, were treated with

Table 6 Type of amputation and time to follow-up for the sample

\begin{tabular}{|c|c|c|c|c|c|}
\hline Patient & $\begin{array}{l}\text { Time to } \\
\text { amputation } \\
\text { (in days) }\end{array}$ & $\begin{array}{l}\text { Type of } \\
\text { amputation }\end{array}$ & $\begin{array}{l}\text { *IRSD } \\
\text { score }\end{array}$ & **Decile & ***Percentile \\
\hline 1 & 3 & Left $4^{\text {th }}$ ray & 897 & 1 & 9 \\
\hline \multirow[t]{2}{*}{2} & 29 & $\begin{array}{l}\text { Right below } \\
\text { knee }\end{array}$ & 820 & 1 & 3 \\
\hline & 11 & $\begin{array}{l}\text { Right above } \\
\text { knee }\end{array}$ & & & \\
\hline 3 & 13 & Left $2^{\text {nd }}$ digit & 1034 & 8 & 71 \\
\hline 4 & 1 & Left ray & 820 & 1 & 3 \\
\hline 5 & 1 & Left $4^{\text {th }}$ digit & 1011 & 7 & 63 \\
\hline
\end{tabular}

*IRSD: The Index of Relative Socioeconomic Disadvantage.

**The lowest $10 \%$ of areas are given decile 1.

***The lowest $1 \%$ of areas are given a percentile 1. 
temporary footwear [14]. Interestingly, the low rate (2\%) of TCC application in our study was consistent with the rate reported in the USA (1.7\%) [39].

The ulcer types were heterogeneous ranging from superficial to deep involving tendon, bone and joint with infection and ischaemia. A total of $11.8 \%$ patients had UT Wound Grade $0 \mathrm{C}$ to $3 \mathrm{C}$ (with ischaemia) and $16.6 \%$ Grade 0D to 3D (with infection and ischaemia). Approximately half $(49.7 \%)$ of our cohort exhibited infected ulcers which is lower than the EURODIALE studies (58\%) $[15,40]$. Fifty patients with a diabetic foot ulcer presented with osteomyelitis. The probe to bone is a quick, low cost and efficient screening test to diagnose osteomyelitis in patients with diabetic foot ulcers [27]. However, other screening methods such as bone biopsy and imaging techniques e.g. computerised tomography $(\mathrm{CT})$ scan, X-ray and magnetic resonance imaging (MRI), can also be used to further confirm the presence of osteomyelitis.

This study is limited by the evaluation of patients with diabetes only. There is also a need to consider other factors such as HbA1c, specifying cause of ulcers due to foot deformities (such as hallux valgus, clawed toes), foot pathologies (such as fissures and callosities) and biomechanical abnormalities (such as cavus and Charcot foot), medical history such as malignancies/chemotherapy and medications which may impair wound healing. Duration of foot ulcer was generally self-reported which is limitation and unreliable for determining ulcer initiation. The Foot Wound Clinic Registry Data Form we used has yet to be assessed for inter-rater reliability and so interpretative errors relating to ulcer characteristics and classification may have occurred. However, to reduce the potential for error, the Foot Wound Clinic Registry includes training in procedures, data sources, data collection systems and most importantly data definitions and their interpretation. A final limitation is that the data reported were derived from a retrospective analysis of a single site and excluded other diabetic foot clinics in Western Sydney.

\section{Future research}

There is a paucity of information on predictive values of risk factors for diabetic foot ulcerations in the Australian health care setting. Therefore in-depth information gained from this study will be useful in developing a risk assessment-model for a larger prospective cohort study. This will enable clinicians to identify and estimate the risk factors associated with diabetic foot ulcers (such as patient co-morbidities, history and physical examination). For comparison, future studies should also evaluate people without diabetes who present with foot ulcers.

\section{Conclusion}

In Western Sydney, diabetic foot ulcers largely affect overweight older males beneath the plantar aspect of the foot with a duration of 1 week to 3 months. These findings are in accordance with the EURODIALE Study. Furthermore our results suggest that socioeconomic status is not related to diabetic foot ulcer characteristics in Western Sydney.

\section{Abbreviations}

ABS: Australian Bureau of Statistics; BMI: Body mass index; DM: Diabetes mellitus; EURODIALE: European Study Group on Diabetes and the Lower Extremity; IQR: Interquartile range; PEDIS: Perfusion, extent/size, depth/tissue loss, infection and sensation; TCC: Total contact cast; UT: University of Texas.

\section{Competing interests}

The authors declare that they have no competing interests.

\section{Authors' contributions}

$\mathrm{NHZ}, J \mathrm{~B}, \mathrm{KH}$ conceived the idea and designed the study, extracted the data, performed the statistical analysis, contributed to the discussion, wrote and reviewed/ edited the manuscript. MV and JPF designed, contributed to discussion and reviewed/ edited the manuscript. LB contributed to the study design and review of the manuscript. All authors have read and approved the final manuscript.

\section{Acknowledgements}

We would like to thank the Westmead Hospital Foot Wound Clinic team: Cherin Obeid-Charrouf, Clare McGloin, Vesna Sakic, Zahia Ters, Suzanne Flower, Gill Gale and Jill Sparks who were involved in the data collection. We would also like to thank Toni Mathieson for her assistance with the database entry and retrieval.

Preliminary work for this study was accepted and presented orally at the Australasian Podiatry Council Conference in Sydney, Australia 2-5 June 2013. The abstract was published in the Journal of Foot and Ankle Research 2013, 6 (Suppl 1):013 (31 May 2013).

\section{Author details}

${ }^{1}$ Arthritis and Musculoskeletal Research Group, The University of Sydney, Sydney, NSW, Australia. ${ }^{2}$ Foot Wound Clinic, Department of Surgery, The University of Sydney, Westmead Hospital, Sydney, NSW, Australia. ${ }^{3}$ Westmead Research Centre for the Evaluation of Surgical Outcomes, Department of Surgery, The University of Sydney, Sydney, NSW, Australia.

Received: 5 February 2014 Accepted: 29 August 2014

Published online: 28 September 2014

\section{References}

1. National Diabetes Service Scheme: Diabetes Australia. Canberra: 2012. Retrieved from http://www.ndss.com.au/.

2. International Diabetes Federation: IDF Diabetes Atlas. 6th edition. Brussels, Belgium: International Diabetes Federation; 2012.

3. International Working Group on the Diabetic Foot: Epidemiology of Diabetic Foot Infections in a Population Based Cohort. Noordwijkerhout, the Netherlands: Paper presented at: International Consensus on the Diabetic Foot; 2003.

4. Lavery LA, Armstrong DG, Wunderlich RP, Tredwell J, Boulton AJ: Diabetic foot syndrome: evaluating the prevalence and incidence of foot pathology in Mexican Americans and non-Hispanic whites from a diabetes disease management cohort. Diabetes Care 2003, 26:1435-1438.

5. Young L: Identifying infection in chronic wounds. Wound Pract Res 2012, 20:38-44.

6. Boulton AJM: The diabetic foot: grand overview, epidemiology and pathogenesis. Diabetes Metab Res Rev 2008, 24:S3-S6.

7. Boulton AJM: The diabetic foot: a global view. Diabetes Metab Res Rev 2000, 16(Suppl 1):S2-S5. 
8. Nyamu PN, Otieno CF, Amayo EO, McLigeyo SO: Risk factors and prevalence of diabetic foot ulcers at Kenyatta National Hospital, Nairobi. East Afr Med J 2003, 80:36-43.

9. El-Nahas MR, Gawish HMS, Tarshoby MM, State OI, Boulton AJM: The prevalence of risk factors for foot ulceration in Egyptian diabetic patients. Pract Diabetes Int 2008, 25:362-366.

10. Mahe E, Langlois G, Baron G, Girard L, Macrez A, Fargeot C, Crickx B: Results of a comprehensive hospital-based wound survey. J Wound Care 2006, 15:381-384

11. Lazzarini PA, O'Rourke SR, Russell AW, Derhy PH, Kamp MC, D'Emden MC, Kinnear EW: Queensland's high risk foot database: tracking the length and width of Queensland's foot ulcers. J Foot Ankle Res 2013, 6:021.

12. National Association of Diabetes Centres: Final Report. Australia: Australian National Diabetes Information Audit \& Benchmarking (ANDIAB); 2009. http://www.health.gov.au/internet/publications/publishing.nsf/Content/ pq-diabetes-pubs-andiab11-toc.

13. Centres NAoD: Final Report. Australia: Australian National Diabetes Information Audit \& Benchmarking (ANDIAB); 2011. http://www.health.gov.au/internet/ publications/publishing.nsf/Content/pq-diabetes-pubs-andiab11-toc.

14. Akhtar S, Schaper N, Apelqvist J, Jude E: A review of the Eurodiale studies: what lessons for diabetic foot care? Curr Diab Rep 2011, 11:1-8.

15. Prompers L, Huijberts $M$, Apelqvist J, Jude E, Piaggesi A, Bakker K, Edmonds M, Holstein P, Jirkovska A, Mauricio D, Ragnauson Tennvall G, Reike $H$ Spraul M, Uccioli L, Urbancic V, Van Acker K, Van Baal J, Van Merode F, Schaper N: High prevalence of ischaemia, infection and serious comorbidity in patients with diabetic foot disease in Europe. Baseline results from the Eurodiale study. Diabetologia 2007, 50:18-25.

16. Campbell LV, Graham AR, Kidd RM, Molloy HF, O'Rourke SR, Colagiuri S: The lower limb in people with diabetes. Position statement of the academy of the Australian Diabetes Society. Med J Aust 2000, 173:369-372.

17. Bakker KFA, van Houtoum WH, Riley P: International Diabetes Federation and International Working Group of the Diabetic Foot. In Time to Act, Diabetes and Foot Care. The Netherlands: 2005.

18. National Evidence-Based Guideline on Prevention: Identification and Management of Foot Complications in Diabetes (Part of the Guidelines on Management of Type 2 Diabetes). Melbourne Australia: 2011. Retrieved from http://www.nhmrc.gov.au/_files_nhmrc/publications/attachments/diabetes_ foot_full_guideline_23062011.pdf.

19. WHO/IDF: Definition and Diagnosis of Diabetes Mellitus and Intermediate Hyperglycaemia. In Report of WHO/IDF Consultation. 2006. http://www.who.int/diabetes/publications/diagnosis_diabetes2006/en/.

20. Prompers L, Schaper N, Apelqvist J, Edmonds M, Jude E, Mauricio D, Uccioli L, Urbancic V, Bakker V, Holstein P, Jikovska A, Piaggesi A, Ragnarson Tennvall G, Reike H, Spraul M, Van Acker K, Van Merode F, Ferreira I, Huijberts M: Prediction of outcome in individuals with diabetic foot ulcers: focus on the differences between individuals with and without peripheral arterial disease. The EURODIALE Study. Diabetologia 2008, 51:747-755

21. Schaper NC, Andros G, Apelqvist J, Bakker K, Lammer J, Lepantalo M Mills JL, Reekers J, Shearman CP, Zierler RE, Hinchliffe RJ: Diagnosis and treatment of peripheral arterial disease in diabetic patients with a foot ulcer. A progress report of the International Working Group on the Diabetic foot. Diabetes Metab Res Rev 2012, 28:218-224.

22. Schaper NCAG, Apelqvist J, Bakker K, Lammer J, Lepantalo M, Mills JL, Reekers J, Shearman CP, Zierler RE, Hinchliffe RJ: Specific guidelines for the diagnosis and treatment of peripheral arterial disease in a patient with diabetes and ulceration of the foot 2011. Diabetes Metab Res Rev 2012, 28:236-237.

23. Australian Bureau of Statistics: Australian Bureau of Statistics Census Community Profiles 2011. Available at: http://www.abs.gov.au/websitedbs/ censushome.nsf/home/seifa 2013.

24. Australian Bureau of Statistics: 2033.0.55.001 - Census of Population and Housing. Australia: Socio-Economic Indexes for Areas (SEIFA); 2011. IRSD. 2011. Available at: http://www.abs.gov.au/ausstats/abs@.nsf/DetailsPage/ 2033.0.55.0012011?OpenDocument 2011 Last accessed 19 June 2014.

25. Australian Bureau of Statistics: Technical Paper Socio-Economic Index for Areas (SEIFA) 2011. Available at: http://www.abs.gov.au/ausstats/abs@.nsf/ Lookup/by\%20Subject/2033.0.55.001 2011 Main\%20Features Technical\% 20Paper 5 Last accessed 6 June 2014.
26. Schaper NC: Diabetic foot ulcer classification system for research purposes: a progress report on criteria for including patients in research studies. Diabetes Metab Res Rev 2004, 20:590-\$95.

27. Morales Lozano R, Gonzalez Fernandez ML, Martinez Hernandez D, Beneit Montesinos JV, Guisado Jimenez S, Gonzalez Jurado MA: Validating the probe-to-bone test and other tests for diagnosing chronic osteomyelitis in the diabetic foot. Diabetes Care 2010, 33:2140-2145.

28. Lavery LA AD, Harkless LB: Classification of diabetic foot wounds. J Foot Ankle Surg 1996, 35:528-531.

29. Burns J, Begg L: Optimising the offloading properties of the total contact cast for plantar foot ulceration. Diabet Med 2011, 28:179-185.

30. Perrin B: A retrospective audit of a diabetic foot clinic. Australas J Podiatr Med 2006, 40:23-25.

31. Merza Z, Tesfaye S: The risk factors for the diabetic foot ulceration. Foot 2003, 13:125-129.

32. Wu S, Armstrong D: Risk assessment of the diabetic foot and wound. Int Wound J 2005, 2:17-24

33. Shammas NW: Epidemiology, classification, and modifiable risk factors of peripheral arterial disease. Vasc Health Risk Manag 2007, 3:229-234

34. Mustoe T: Understanding chronic wounds: a unifying hypothesis on their pathogenesis and implications for therapy. Am J Surg 2004, 187:65S-70S.

35. Hess CT: Checklist for factors affecting wound healing. Adv Skin Wound Care 2011, 24:4.

36. Australian Bureau of Statistics: 2033.0.55.001 - Census of Population and Housing. Australia: Socio-Economic Indexes for Areas (SEIFA); 2011. Available at: http://www.abs.gov.au/ausstats/abs@.nsf/mf/2033.0.55.001/ Last accessed 19 June 2014

37. Atlindas M, Kilic A, Cinar C, Bingo UA, Ozturk G: The epidemiology of foot wounds in patients with diabetes. A description of 600 consecutive patients in Turkey. J Foot Ankle Surg 2011, 50:146-152.

38. van Duersen $R$ : Mechanical loading and off-loading of the plantar surface of the diabetic foot. Chronic Infect Dis 2004, 39:587-S91.

39. Wu SC, Jensen JL, Weber AK, Robinson DE, Armstrong DG: Use of pressure offloading devices in diabetic foot ulcers. Do we practice what we preach? Diabetes Care 2008, 31:2118-2119.

40. Schaper NC: Lessons from Eurodiale. Diabetes Metab Res Rev 2012, 28(Suppl 1):21-26.

doi:10.1186/s13047-014-0039-4

Cite this article as: Haji Zaine et al:: Characteristics of diabetic foot ulcers in Western Sydney, Australia. Journal of Foot and Ankle Research 2014 7:39.

\section{Submit your next manuscript to BioMed Central and take full advantage of:}

- Convenient online submission

- Thorough peer review

- No space constraints or color figure charges

- Immediate publication on acceptance

- Inclusion in PubMed, CAS, Scopus and Google Scholar

- Research which is freely available for redistribution 